\title{
Biological Reconstruction in Malignant Bone Tumors
}

\section{Malign Kemik Tümörlerinde Biyolojik Rekonstrüksiyon}

\author{
İsmail Burak Atalay, Mehmet Akif Şimşek, Özgür Irak, Mehmet Fatih Ekşioğlu, Bedii Şafak Güngör
}

Sağlık Bakanlığı Ankara Onkoloji Eğitim Ve Araştırma Hastanesi Ortopedi Ve Travmatoloji Kliniği, Ankara, Türkiye

\begin{abstract}
ÖZET
GíRiş ve AMAÇ: Malign kemik tümörleri cerrahisi sonrası oluşan defektlerin giderilmesinde farklı rekonstrüksiyon yöntemleri kullanılabilir. Bu çalışmada primer malign kemik tümörleri cerrahisi sonrası kemik defektlerinin biyolojik rekonstrüksiyon yöntemi ile tedavisini ve fonksiyonel sonuçlarımızı değerlendirmeyi amaçladık.
\end{abstract}

YÖNTEM ve GEREÇLER: 2003-2017 yılları arası primer malign kemik tümörü nedeniyle biyolojik rekonstrüksiyon uygulanan 24 hasta çalışmaya alındı. Hastaların 11'i Ewing sarkom, 8'i osteosarkom, 2‘si malign dev hücreli tümör, 2'si kondrosarkom ve 1'i fibrosarkom tanılı idi. 18 olguda otogreftleme, 1 olguda adjuvan sıvı nitrojen sonrası otogreftleme ve 5 olguda distraksiyon osteogenezisi ile kemik transportu yöntemi kullanıldi.

BULGULAR: Hastaların 14'ü erkek,10'u kadın olup ortalama yaş 18.6(5-42), takip süresi 41.4 ay (10-78 ay) ve rezeksiyon sonrası ortalama kemik defekti $10.7 \mathrm{~cm}$ idi (4-22). Ortalama MSTS skorları kemik transportuyla rekonstrükte edilenlerde 77.3 ve otogreft uygulananlarda 74.5 olarak bulundu. Ortalama DASH skoru 2.29(2.02.65), Knee Society ortalama diz skorları 72.4(60-89) ve fonksiyon skorları 76.2 (65-91)idi. Avasküler fibuler greft uygulanan hastalardan 3'ünde kaynamama (\%17.6),1'inde greft fraktürü görüldü. Hiçbir hastada nörovasküler komplikasyon görülmedi.3 hastada pin dibi enfeksiyonu görüldü. TARTIŞMA ve SONUÇ: Ekstremite koruyucu cerrahi uygulanırken primer tümörün takip ve tedavisini etkileyecek rekonstrüksiyonlardan kaçınılmalıdır.Yaşlı,yüksek gradeli tümörü olan, tedavi kooperasyonu olmayan hastalarda modüler endoprotezlerle rekonstrüksiyon ilk tedavi seçeneğidir.Ancak kemik gelişimi tamamlanmamış,yaşam beklentisi uzun ve kooperasyonu tam hastalarda biyolojik rekonstrüksiyon;kaynamama,greft komplikasyonları ve uzun tedavi süreçleri gibi zorluklara rağmen canlı kemik dokusuyla rejenarasyon sağlaması bakımından ön plana çıkmaktadır.Yakın gelecekte kaynamayı ve greft hipertrofisini arttırıcı,komplikasyonları azaltıcı adjuvan faktörlerin kullanıma girmesi ile biyolojik rekonstrüksiyon yöntemlerinin kullanımının artacağını düşünmekteyiz.

Anahtar Kelimeler: Biyolojik rekonstrüksiyon, malign kemik tümörü, distraksiyon osteogenezisi, otolog kemik grefti

ABSTRACT
INTRODUCTION: There may be several reconstruction methods in order to eliminate the defects developed
after the surgery of malignant bone tumors. In this study, we aimed to evaluate our functional results in the
treatment of bone defects by biological reconstruction method after primary malign bone tumor surgery.
METHODS: Between $2003-2017$ years, 24 patients with primary malignant bone tumors undergone biological
reconstruction were included into study. 11 of the patients had Ewing's sarcoma, 8 of them had osteosarcoma, 2 of
them had malignant giant cell tumor, 2 of them had chondrosarcoma and 1 of them had fibrosarcoma.
Autografting were applied in 18 cases, autografting after liquid nitrogen in 1 case and bone transport after
distraction osteogenesis were applied in 5 cases. RESULTS: 14 of the patients were male,10 of them were female. The mean age was 18.6(5-42), follow-up period was 41.4 months (10-78) and bony defect was $10.7 \mathrm{~cm}$ (4-22). Mean MSTS scores was 77.3 reconstructed with bone transport and 74.5 undergone autografting. DASH score was 2.29(2.0-2.65), knee Society scores were $72.4(60-89)$ and the functional scores were 76.2 (65-91). There were nonunion in 3 cases undergone avascular fibulare grafting (\%17.6) and 1 graft fracture. No neurovascular complication in any of the patients.Pin-tract infection was observed in 3 patients.

DISCUSSION and CONCLUSION: One must avoid reconstructions that may affect the follow-up and treatment of the primary tumor when applying extremity-sparing surgery.Reconstruction with endoprosthesis must be the first-line option in the patients who are old,has high-grade tumor and has not treatment 
cooperation.On the other hand, for the patients with long survey with cooperation and ongoing bone development, biological reconstruction comes into prominence in terms of its regeneration providing nature with live bone tissue despite the shortcomings like nonunion, graft fracture and long treatment periods.In near future, we expect an increase in the use of biological reconstruction methods as some adjuvant factors that are facilitating union,graft hypertrophy and decreasing complications put into use.

Keywords: Biological reconstruction, malignant bone tumor, distraction osteogenesis, autologous bone graft

\section{GİRiş}

Kemoterapi protokolleri ve erken tan yöntemlerindeki gelişmeler sonrasında malign kemik tümörlü hastaların sağkalım süreleri artmakta ve geçmişte amputasyon cerrahisi ile tedavi edilen bu hastalar artık lokal nüks oranı amputasyon cerrahisine yakın olan ekstremite koruyucu cerrahi ile tedavi edilebilmektedirler.(1) Cerrahi sonrası oluşan eklem ve çevresi defektler çoğunlukla modüler protezler ile rekonstrükte edilir.(2) Allogreftlerle uygulanan rekonstrüksiyonlar endoprotezlere alternatif olarak geliştirilmiştir ve bu yöntemde karşılaşılan en büyük problemler, eklem instabilitesi ve eklem uyumudur.(3) Yüksek radyoterapi ile yaşayan tümör hücreleri öldürülmüş rezeksiyon materyalinin tekrar implantasyonu, yüksek enfeksiyon oranları, revaskülarizasyonun çok geç olması ve kırık oranları nedeniyle cazip görülmemektedir.(4) Özellikle büyümenin devam ettiği erken çocukluk yaş grubunda defektlerin rekonstrüksiyonu büyük bir problemdir. Bu problemin çözümünde yaşayan kemik dokusu ile rekonstrüksiyon kurtarıcı bir yaklaşım olarak ön plana çıkmaktadır. $(5,6)$ Biyolojik rekonstrüksiyon için klinik çalışmalarda kullanılan iki yol distraksiyon osteogenezisi ve kemik grefti uygulamalarıdır. Çalışmamızda biyolojik rekonstrüksiyon uyguladığımız primer malign kemik tümörlü hastaların fonksiyonel sonuçlarını değerlendirdik.

\section{GEREÇ VE YÖNTEM}

Kliniğimizde primer malign kemik tümörü nedeniyle biyolojik rekonstrüksiyonla tedavi edilmiş 24 hasta çalışmaya alındı. Hastaların 14'ü erkek (\%58.3), 10’u kadın (\%41.7) olup, ortalama yaş $18.6 \quad(5-42)$ idi. Otogreft uygulanan olgularda tümör rezeksiyonu sonras1 oluşan kemik defekti ortalama $10.7 \mathrm{~cm}$ idi (4$22 \mathrm{~cm})$. Hastaların takip süresi kemik transportu yapilan grupta ortalama 51 ay (3065 ay) ve otogreft rekonstrüksiyonu uygulanan grupta ortalama 40.5 aydı (10-78 ay). Tüm olgular preoperatif direk grafi, tüm vücut kemik sintigrafisi, manyetik rezonans görüntüleme ve bilgisayarlı tomografi ile değerlendirildi. Biyolojik rekonstrüksiyon yöntemi olarak 18 olguda otogreftleme, 1 olguda adjuvan siv1 nitrojen sonras1 otogreftleme ve 5 olguda distraksiyon osteogenezisi kullanıldı Tümör lokalizasyonlarına göre; 5'er olgu tibia proksimal ve tibia distal, 3 'er olgu humerus proksimal ve femur diafiz, 2 olgu femur distal ve 1'er olgu da radius distal, iliak kanat, kalkaneus, klavikula, ulna distal ve fibula distal yerleşimli idi. (Tablo 1) Otogreft rekonstrüksiyonlarında olguların histopatolojik tanılara göre dağılımı; 8 hastada Ewing sarkom, 5 hastada Osteosarkom, 2 hastada Malign dev hücreli tümör, 2 hastada Kondrosarkom ve 1 hastada Fibrosarkomdu. Rekonstrüksiyonlarda; 1 olguda vasküler pediküllü fibula, 13 olguda avasküler fibula, 3 olguda avasküler iliak kanat ve 1 olguda avasküler iliak kanat ve anterior tibial korteks kullanıldı. Greftlerin 13'ü segmenter ve 5'i osteoartiküler yapıdaydı. Greftlerin alıcı sahadaki osteosentezinde 14 olguda DCP (dinamik kompresyon plağı) plak-vida, 4 olguda ilizarov eksternal fiksatörü kullanıldı. (Tablo 2) Fibuler greftlerin alımında, supin pozisyonda lateral yaklaşım tercih edildi. İliak kanat greftleri spina iliaka anterior süperior palpe edilerek planlanan greft boyuna uygun insizyon kullanılarak osteotom kullanılarak alındı. Büyük boyutta osteoartiküler ya da 
segmenter fibuler greft kullanılan olgularda verici sahada gelişebilecek ayak bilek instabilitesini ve valgus deformitesini önlemek için greft alındıktan sonra distal tibiofibuler sindesmoz, vida ile tespit edildi. (Resim 1) Distraksiyon osteogenezisi yöntemi 5 hastada kullanıldı. 4 hastada sirküler 1 hastada unilateral fiksatör kullanıldı. Olguların 1'i kadın 4'ü erkek olup ortalama yaşları 15.6 (730 y1l)idi. 3 hasta osteoarkom ve 2 hasta da Ewing Sarkom tanılı idi. Rekonstrüksiyonlar 2 olguda tibia distali ve proksimaline ve 1 olguda da femur diafizine uygulandi. 7-10 günlük latent dönemi takiben distraksiyonlara 4x0.25 mm/gün hızında başlandı. 1 hastada (olgu 19) geniş tümör rezeksiyonu sonrası etkili bir kriyojenik ajan olan sıv1 nitrojenle kemiğin intraoperatif adjuvan terapisinin ardından, temizlenmiş kemiğin yeniden rezeksiyon sahasına nakil işlemi uygulandı.

\section{BULGULAR}

Hastaların takip sonuçları radyolojik ve fonksiyonel olarak değerlendirildi. Radyolojik değerlendirmede nüks, distraksiyon takibi, greft ve hedef nokta kaynama durumuna bakıldı. Takip süreleri içinde hiçbir olguda lokal nükse rastlanmadı. Fonksiyonel sonuçların değerlendirilmesinde Musculoskeletal Tumor Society (MSTS) skalas1, DASH (Disabilities of arm, Shoulder and Hand) skoru ve Knee Society Skoru kullanıldı. Genel fonksiyonel sonuçlar Musculoskeletal Tumor Society (MSTS) fonksiyonel skalasına göre belirlendi. (Tablo 3). Ortalama MSTS fonksiyonel sonuçları kemik transportu ile rekonstrükte edilenlerde 77.3 (2 mükemmel, 3 iyi sonuç), otogreftle rekonstrüksiyon uygulananlarda $74.5 \quad$ (5 mükemmel, 9 iyi, 4 orta sonuç) olarak değerlendirildi. Tüm serinin ortalama MSTS skoru 75.1 olarak bulundu. Üst ekstremite fonksiyonlarının değerlendirilmesinde DASH (Disabilities of arm, Shoulder and Hand) skoru kullanıldı. $\mathrm{Bu}$ skala hastanın günlük aktivitelerini, sosyal durumunu, semptomlarını ve uyku durumunu değerlendirmekte olup mükemmel sonuç 1.0 iken, kötü sonuç 5.0 olarak değerlendirilir. Uyguladığımız üst ekstremite rekonstrüksiyonlarında ortalama DASH skoru; 2.29 (2.0-2.65) olarak bulundu. (Tablo 4) Alt ekstremite diz fonksiyonlarını değerlendirmek için Knee Society Skoru kullanıldı. Bu skala diz skoru ve fonksiyonel durum değerlendirmelerinin yer aldığ 2 bölümden oluşur ve ağr1, fleksiyonekstansiyon açıklığı, yürüme, merdiven çıkma, yardımc1 ortez kullanımını sorgular. Diz çevresinde rekonstrüksiyon uyguladığımız olguların Knee Society Skalası'na göre ortalama diz skorları 72.4 (60-89) ve fonksiyon skorlar1 ortalama 76.2 (65-91) olarak bulundu. (Tablo 5) DCP plak-vida ile fiksasyon yapilan Olgu 2'de meydana gelen topukta varus ve distalde kaynamama ile Olgu 3'de karşılaşılan kaynamama komplikasyonları ilizarov eksternal fiksatörüyle uygulanan kompresyondistraksiyon manevraları ile çözüldü. (Resim 2) İlizarov eksternal fiksatörü kullanılan olgu 8'in takiplerinde gelişen varus açılanması, greft fraktürü ve kısalığa yönelik plak-vida ile fiksasyon ve epifizyodez uygulandi. (Resim 3) Olgu 11'deki kaynamama ve kisalık komplikasyonlarına yönelik ise intrameduller çivi ile artrodez uygulandi. 3 hastada pin dibi enfeksiyonu görüldü. Hepsi uygun antibiyoterapi ile tedavi edildi. Hiçbir hastada debritman gerektiren derin enfeksiyon gözlenmedi. (Resim 4)

\section{TARTIŞMA}

Ekstremite koruyucu cerrahide günümüzde uygulanan biyolojik rekonstrüksiyon yöntemleri arasında kemik doku mühendisliği, distraksiyon osteogenezisi ve vasküler/avasküler otogreftler yer alır. $(6,7)$ Kemik doku mühendisliği ile ilgili deneysel çalışmalar devam ederken henüz etkin ve uzun takipli geniş seriler mevcut değildir. Geniş rezeksiyon kavramı radyodiagnostik alandaki gelişmelerle yerini gerektiği kadar rezeksiyon 
kavramına bırakmıştır. Kaybedilen dokunun rekonstrüksiyonunun ne kadar zor olduğu düşünüldüğünde bu kavram önem kazanmaktadır. Cerrahi sınırların tespitinde ve özellikle meduller yayılımın belirlenmesinde; manyetik rezonans görüntüleme altın standart tetkikdir. (8) Vasküler otogreft rekonstrüksiyonlarında vasküler pedikülün değerlendirilmesinde multislice anjiyotomografi ve kemik sintigrafisi kullanılır. $(8,9)$ Çalışmamızda vasküler pediküllü otogreft uygulamamizın kanlanmasinın değerlendirilmesinde üç fazlı kemik sintigrafisi ve anjiyografiden yararlandık. Tümör rezeksiyonları sonrası endoprotez rekonstrüksiyonlarında büyüme ve aktivite ile protezin gevşemesi, periprostetik kırıklar, enfeksiyon ve ağrılı uzatma prosedürleri gibi problemlerle karşılaşılır. (10) Seçilmiş hastalarda distraksiyon osteogenezisi ile bu problemlerden kaçınılabilir. Shirai ve ark. (11) tümör rezeksiyonu uyguladıkları 31 hastalık serilerinde endoprotez ile distraksiyon osteogenezisi olgularını karşılaştırmışlar ve k1sa vadede distraksiyon osteogenezisinin komplikasyonlarının fazlalığı ve zayıf fonksiyonel sonuçları nedeniyle dezavantajlı görülse bile, osteogenezis sürecinde komplikasyonlarda azalma görmüşler ve uzun vadede yaşam beklentisi yüksek olan hastalarda distraksiyon osteogenezisinin endoprostetik replasmana göre daha avantajlı olduğunu söylemişlerdir.

Tsuchiya ve ark. (12) distraksiyon osteogenezisinin büyüyen çocuklarda ve uzun dönem prognoz beklentisi olan hastalarda uygun tedavi şekli olduğunu bildirmişler, metastatik hastalarda ise fonksiyonel olarak erken düzelme sağlaması bakımından nonbiyolojik yöntem olan endoprotez uygulamasını önermişlerdir. Lesensky ve ark. (13) 2017 yılında yaptıkları çalışmada distraksiyon osteogenezisinin büyük kemik defektlerinin yapılandırılmasında, ekstremite boy eşitsizliği gibi komplikasyonların çözümünde etkili bir yöntem olduğunu söylemişlerdir. Yang ve ark. distraksiyon osteogenezisinde en önemli başarısızlık nedeninin hasta uyumunun zorluğu olduğunu belirtmişler ve başarılı sonuç için hastaların yakın takip edilerek tedavinin tamamlanmasına yönelik tedbirlerin alınması gerektiğini belirtmişlerdir. (14) Dormans ve ark. 13 yaşında bir Ewing sarkom olgusunda $13 \mathrm{~cm}$.lik defekt için kemik transportu uygulamış, takiplerinde otojen greftleme de kullanarak kaynama sağlamış ve hastanın MSTS fonksiyonel skorunu $\% 80$ olarak bildirmişlerdir. (15) Serimizde 3 osteosarkom ve 2 Ewing sarkom tanıl hastaya ilizarov eksternal fiksatörle kemik transportu yöntemini kullandık. $\mathrm{Bu}$ grupta ortalama MSTS skorumuz 77.3 idi. Distraksiyon osteogenezisi sonrası en fazla görülen komplikasyonlar; pin dibi enfeksiyonları, kaynamama, kırı, ROM kısıtlılığı ve kısalıktır. Olgularımızda en fazla pin dibi enfeksiyonlarıyla (\%40) karşılaştık. $\mathrm{Bu}$ hastalarda cerrahi debritmana ya da tel çıkarımına ihtiyaç olmadı. Hedef noktada kaynama yetersizliği sorunu ile serimizdeki iki hastada karşılaştık. Ardışı kompresyon distraksiyon manevraları ile bir hastada 3, diğerinde ise 4 ayda yeterli kaynamaya ulaştık. Literatürdeki distraksiyon osteogenezisi serilerinde karşıllaşılan komplikasyon farklılıklarının nedeni bu yöntemin yaş, uzatma miktarı, beslenme, sosyo-kültürel durum ve özellikle kemo/radyoterapi protokolleri gibi birçok değişkenden etkilenmesine bağlıdır. Friedlander ve ark. (16) ratlar üzerinde kisa dönem metotreksat ve doksorubisinin kemik üzerine etkisini incelemişler ve osteogenezisin baskılandığını bildirmişlerdir. Prevot ve ark. (17) kemoterapinin osteogenezisi yavaşlattı̆̆ını ancak tam durdurmadığını söylemişlerdir. Ozaki ve ark. (18) adjuvan kemoterapinin osteogenezisi yavaşlattığını ve fiksatör kullanım süresini uzattığını belirtmişler, karşılaştıkları yüksek komplikasyon oranlarını kemoterapinin immunsupressif etkisine bağlamışlardır. Kemik transportu uyguladığımız ve kemoterapi alan hastaların 2 
tanesinde hedef noktada kaynama yetersizliği dışında direkt kemoterapinin etkisine bağlayacağımız ve tedaviyi sonlandırmamızı gerektirecek olumsuz etkiye rastlamadik. Literatürle uyumlu olarak adjuvan kemoterapinin osteogenezisi yavaşlattığını düşünmekteyiz. Rezeke edilen kemiğin adjuvan sıvı nitrojene maruz birakılıp ardından otogreft olarak kullanılması da biyolojik rekonstrüksiyon yöntemlerinden biridir. Sıv1 nitrojen etkili bir kriyojenik ajandır. $(19,20)$ Rahman ve ark. (19) 28 hastalık serilerinde tümör rezeksiyonu sonrası kemiği sıv1 nitrojende bekletmiş ve 2 hastada nüks gördüklerini bildirmişlerdir. Sağ femur diafiz Ewing sarkom tanılı hastamızda tümöral kemiğin rezeksiyonunu takiben adjuvan siv1 nitrojen kullandık. Otogreft literatürde önerildiği gibi 20 dakika sıv1 nitrojende birakıld1ktan sonra 15 dakika saline solüsyonunda bekletilip uyguland. Biyolojik rekonstrüksiyonlarda en sık kullanılan yöntem otogreft uygulamasıdır. Özellikle üst ekstremitede fonksiyonel rekonstrüksiyon sağlar. (21) Avasküler otogreftlerde kaynamama/gecikmiş kaynama ve yorgunluk kırıkları görülebilir. Enneking ve ark. (22) avasküler greftlerde kaynamama oranını $\% 32$ ve yorgunluk kırı̆g 1 oranını $12 \mathrm{~cm}$ 'den uzun greftlerde $\% 58$ olarak rapor etmişlerdir. Donati ve ark. (23) ise \%49 kaynamama ve \%27 yorgunluk kırığı oranları ile karşılaşmışlardır. Vasküler otogreftlerde ortalama kaynama süreleri değerlendirildiğinde Chen ve ark. (24), 14 hastanın 11'inde sorunsuz kaynama elde etmişlerdir. Serimizde avasküler greft uyguladığımız 17 hastanın 3 tanesinde kaynamama (\%17.6) ve 1 tanesinde de (\% 5.88) kırığa rastladık. Hastaların ortalama kaynama süresi 8 aydı. Uygulamalarımızda literatüre oranla daha az komplikasyonla karşılaşmamızın sebebini vaka sayımızın çok yüksek olmamasına, grefti rekonstrüksiyon safhasından hemen önce donör sahadan ayırmamıza dolayısıyla iskemi süresinin kısa olmasına ve hastaların yakın takibine bağlıyoruz. En sık karşılaşılan sorunlardan olan kaynamama probleminin hasta uyumsuzluğuna bağlı fizyolojik yüklenmelerin sağlanamaması ve uygulanan kemoterapi protokolü ile ilişkili olduğunu düşünüyoruz. Ayrıca tespit yönteminin önemli olduğunu, eksternal fiksatör kullanımının periosteal ve endosteal dolaşımın engellenmesi sorununu en aza indirgediğini düşünmekteyiz. Çocukluk çağı otogreft uygulamalarında donör saha morbiditeleri görülebilir. Gonzales ve ark. (25) $2 \mathrm{~cm}$.den fazla fibula rezeke ettikleri ortalama 5.5 yaşındaki 23 hastanın \%75'inde fibula başı migrasyonuna ve $\% 20$ 'sinde tibia diafizinde valgus deformitesine rastlamışlar, 13 yaşından küçüklerde proflaktik sindesmoz tespitini önermişlerdir. Çalışmamızda 9 ve 13 yaşındaki iki hastada (olgu 3 ve 6) ayn seansta sindesmoz vidası ile distal fibulayı tespit ettik. Tümör cerrahisinde tüm tedaviler olgunun prognozunu etkilemeyecek ve mevcut survisinde olguya en faydalı olacak şekilde düzenlenmelidir. Artroplasti hareketin korunması ve erken fonksiyonel restorasyon sağlayabilme gibi avantajlara sahip bir rekonstrüksiyon yöntemi olup, yaşlı yüksek gradeli tümörü olan, hayat beklentisi kısa olan hastalarda tartışmasız ilk seçenek yöntemdir. Henüz kemik gelişimi tamamlanmamış çocuklarda ve yaşam beklentisi uzun olan, tedaviye koopere olabilecek hastalarda tedavi sürecindeki zahmetlerine rağmen biyolojik rekonstrüksiyonun endoprotez uygulamasina göre daha avantajlı olduğu görüşündeyiz. Gelecekte distraksiyon osteogenezisinde kaynamayı hızlandırıcı, pin dibi enfeksiyonlarını önleyici, otogreft rekonstrüksiyonlarında da greft hipertrofisini ve kaynamayı arttırıc1, komplikasyonları azaltıcı non invaziv veya mini invaziv adjuvan tedavi protokollerinin bulunması ve klinik kullanıma girmesi ile; zamanın çok önemli olduğu tümör tedavisinde biyolojik rekonstrüksiyon yöntemlerinin yaygın kullanımının artacağı düşüncesindeyiz. 
Çıkar Çatışması: Yok

Table 1. Kemik tümör rezeksiyonu sonrasında biyolojik rekonstrüksiyon uygulanan olguların karakteristikleri

\begin{tabular}{|c|c|c|c|c|c|c|}
\hline $\begin{array}{l}\text { OLGU } \\
\text { NO }\end{array}$ & YAŞ/CINS & TANI & $\begin{array}{l}\text { ANATOMİK } \\
\text { YERLEŞIM }\end{array}$ & $\begin{array}{l}\text { TÜMÖR } \\
\text { BOYUTU }\end{array}$ & $\begin{array}{l}\text { TAKİP } \\
\text { SÜRESİ }\end{array}$ & UYGULANAN TEDAVİ \\
\hline 1 & $14 / \mathrm{E}$ & Ewing Sarkom & Tibia proksimal & $14 \mathrm{~cm}$ & 68 ay & Otogreftleme \\
\hline 2 & $24 / \mathrm{K}$ & Osteosarkom & Tibia distal & $8 \mathrm{~cm}$ & 78 ay & Otogreftleme \\
\hline 3 & $13 / \mathrm{K}$ & Osteosarkom & Femur distal & $11 \mathrm{~cm}$ & 45 ay & Otogreftleme \\
\hline 4 & $20 / \mathrm{E}$ & Osteosarkom & Humerus proksimal & $9 \mathrm{~cm}$ & 24 ay & Otogreftleme \\
\hline 5 & $15 / \mathrm{K}$ & Osteosarkom & Humerus proksimal & $8 \mathrm{~cm}$ & 30 ay & Otogreftleme \\
\hline 6 & $9 / \mathrm{K}$ & Ewing Sarkom & Humerus proksimal & $14 \mathrm{~cm}$ & 18 ay & Otogreftleme \\
\hline 7 & $26 / K$ & Malign DHT & Radius distal & $6 \mathrm{~cm}$ & 22 ay & Otogreftleme \\
\hline 8 & $12 / \mathrm{K}$ & Ewing Sarkom & Femur diafiz & $15 \mathrm{~cm}$ & 54 ay & Otogreftleme \\
\hline 9 & $42 / \mathrm{K}$ & Kondrosarkom & İliak kanat & $20 \mathrm{~cm}$ & 48 ay & Otogreftleme \\
\hline 10 & 19/E & Fibrosarkom & Tibia distal & $8 \mathrm{~cm}$ & 32 ay & Otogreftleme \\
\hline 11 & $15 / \mathrm{E}$ & Osteosarkom & Femur distal & $9 \mathrm{~cm}$ & 46 ay & Otogreftleme \\
\hline 12 & $5 / \mathrm{E}$ & Ewing Sarkom & Tibia distal & $8 \mathrm{~cm}$ & 17 ay & Otogreftleme \\
\hline 13 & $23 / \mathrm{E}$ & Malign DHT & Tibia proksimal & $3 \mathrm{~cm}$ & 61 ay & Otogreftleme \\
\hline 14 & $17 / \mathrm{E}$ & Ewing Sarkom & Kalkaneus & $3 \mathrm{~cm}$ & 60 ay & Otogreftleme \\
\hline 15 & $41 / \mathrm{K}$ & Kondrosarkom & Ulna distal & $2 \mathrm{~cm}$ & 63 ay & Otogreftleme \\
\hline 16 & $14 / \mathrm{E}$ & Ewing Sarkom & Klavikula & $6 \mathrm{~cm}$ & 27 ay & Otogreftleme \\
\hline 17 & $35 / \mathrm{E}$ & Ewing Sarkom & Fibula distal & $6 \mathrm{~cm}$ & 26 ay & Otogreftleme \\
\hline 18 & $12 / \mathrm{K}$ & Ewing Sarkom & Tibia proksimal & $6 \mathrm{~cm}$ & 10 ay & Otogreftleme \\
\hline 19 & Şahin can & Ewing Sarkom & Femur diafiz & $12 \mathrm{~cm}$ & 11 ay & S1v1 nitrojen \\
\hline 20 & Çağdaş & Ewing Sarkom & Tibia proksimal & $6 \mathrm{~cm}$ & 65 ay & $\begin{array}{l}\text { Distraksiyon } \\
\text { osteogenezisi }\end{array}$ \\
\hline 21 & $7 / K$ & Osteosarkom & Tibia distal & $3 \mathrm{~cm}$ & 49 ay & $\begin{array}{l}\text { Distraksiyon } \\
\text { osteogenezisi }\end{array}$ \\
\hline 22 & $14 / \mathrm{E}$ & Osteosarkom & Tibia distal & $6 \mathrm{~cm}$ & 30 ay & $\begin{array}{l}\text { Distraksiyon } \\
\text { osteogenezisi }\end{array}$ \\
\hline 23 & $30 / \mathrm{E}$ & Osteosarkom & Tibia proksimal & $6 \mathrm{~cm}$ & 64 ay & $\begin{array}{l}\text { Distraksiyon } \\
\text { osteogenezisi }\end{array}$ \\
\hline 24 & $10 / \mathrm{E}$ & Ewing Sarkom & Femur diafiz & $3 \mathrm{~cm}$ & 47 ay & $\begin{array}{l}\text { Distraksiyon } \\
\text { osteogenezisi }\end{array}$ \\
\hline
\end{tabular}


Table 2. Otogreft rekonstrüksiyonu uygulanan olguların karakteristikleri

\begin{tabular}{|c|c|c|c|c|c|}
\hline OLGU NO & OTOGREFT & $\begin{array}{l}\text { VASKÜLER } \\
\text { YAPISI }\end{array}$ & İSKELET DEFEKTİ & GREFT TİPİ & $\begin{array}{l}\text { OSTEOSENTEZ } \\
\text { TİPİ }\end{array}$ \\
\hline 1 & Fibula & Avasküler & $16 \mathrm{~cm}$ & Segmenter & Sirküler EF \\
\hline 2 & Fibula & Avasküler & $10 \mathrm{~cm}$ & Osteoartiküler & $\begin{array}{l}\text { Plak-vida, Sirküler } \\
\text { Ef }\end{array}$ \\
\hline 3 & Fibula & Avasküler & $13 \mathrm{~cm}$ & Segmenter & $\begin{array}{l}\text { Plak-vida, K teli, } \\
\text { Sirküler Ef }\end{array}$ \\
\hline 4 & Fibula & Vasküler & $11 \mathrm{~cm}$ & Segmenter & Plak-vida \\
\hline 5 & Fibula & Avasküler & $10 \mathrm{~cm}$ & Segmenter & Plak-vida \\
\hline 6 & Fibula & Avasküler & $16 \mathrm{~cm}$ & Osteoartiküler & Plak-vida \\
\hline 7 & Fibula & Avasküler & $8 \mathrm{~cm}$ & Osteoartiküler & Plak-vida \\
\hline 8 & Fibula & Avasküler & $17 \mathrm{~cm}$ & Segmenter & $\begin{array}{l}\text { Plak-vida, Sirküler } \\
\text { Ef }\end{array}$ \\
\hline 9 & Fibula & Avasküler & $22 \mathrm{~cm}$ & Segmenter & Plak-vida, K teli \\
\hline 10 & $\begin{array}{l}\text { İliak kanat, } \\
\text { tibia } \\
\text { ant.korteks }\end{array}$ & Avasküler & $10 \mathrm{~cm}$ & Segmenter & Sirküler EF \\
\hline 11 & Fibula & Avasküler & $11 \mathrm{~cm}$ & Segmenter & Sirküler EF \\
\hline 12 & Fibula & Avasküler & $10 \mathrm{~cm}$ & Segmenter & Plak-vida \\
\hline 13 & İliak kanat & Avasküler & $5 \mathrm{~cm}$ & Segmenter & Plak-vida \\
\hline 14 & İliak kanat & Avasküler & $5 \mathrm{~cm}$ & Segmenter & Plak-vida \\
\hline 15 & İliak kanat & Avasküler & $4 \mathrm{~cm}$ & Segmenter & Plak-vida \\
\hline 16 & Fibula & Avasküler & $8 \mathrm{~cm}$ & Osteoartiküler & Plak-vida, K teli \\
\hline 17 & Fibula & Avasküler & $8 \mathrm{~cm}$ & Osteoartiküler & Plak-vida \\
\hline 18 & Fibula & Avasküler & $9 \mathrm{~cm}$ & Segmenter & Plak-vida \\
\hline
\end{tabular}


Tablo 3

\begin{tabular}{|c|c|c|c|c|}
\hline OLGU NO & $\begin{array}{l}\text { REKONSTRÜKSIYYON } \\
\text { YÖNTEMİ }\end{array}$ & $\begin{array}{l}\text { MSTS FONKSIYYONEL } \\
\text { SKORU }\end{array}$ & KOMPLİKASYON & UYGULANAN TEDAVİ \\
\hline 1 & Otogreft & 86.6 & - & \\
\hline 2 & Otogreft & 73.3 & Topukta varus, kaynamama & $\begin{array}{l}\text { İlizarov sirküler fiksatör ile } \\
\text { korreksiyon }\end{array}$ \\
\hline 4 & Otogreft & 73,3 & - & \\
\hline 5 & Otogreft & 83.3 & - & \\
\hline 7 & Otogreft & 80 & - & \\
\hline 8 & Otogreft & 66.6 & $\begin{array}{l}\text { Varus açılanması, greft } \\
\text { fraktürü,kısalık }(5 \mathrm{~cm})\end{array}$ & $\begin{array}{l}\text { Plak-vida ile fiksasyon, } \\
\text { epifizyodez }\end{array}$ \\
\hline 9 & Otogreft & 66.6 & - & \\
\hline 10 & Otogreft & 66.6 & - & \\
\hline 11 & Otogreft & 63.3 & $\begin{array}{l}\text { Pindibi enf. } \\
\text { kaynamama,kısalık }(7 \mathrm{~cm})\end{array}$ & $\begin{array}{l}\text { Antibiyoterapi, IM çivi ile } \\
\text { artrodez }\end{array}$ \\
\hline 12 & Otogreft & 73.3 & - & \\
\hline 14 & Otogreft & 86.6 & - & \\
\hline 15 & Otogreft & 73.3 & - & \\
\hline 16 & Otogreft & 80 & - & \\
\hline 17 & Otogreft & 73,3 & - & \\
\hline 18 & Otogreft & 73.3 & - & \\
\hline 19 & Siv1 nitrojen & 73.3 & - & \\
\hline 20 & Distraksiyon Osteogenezisi & 73.3 & - & \\
\hline 21 & Distraksiyon Osteogenezisi & 73.3 & Pindibi enf. Kaynama yetersizliği & $\begin{array}{l}\text { Antibiyoterapi, ardışık } \\
\text { kompresyon-distraksiyon } \\
\text { manevraları }\end{array}$ \\
\hline 22 & Distraksiyon Osteogenezisi & 80 & - & \\
\hline 23 & Distraksiyon Osteogenezisi & 73.3 & Pindibi enf.,kaynama yetersizliği & $\begin{array}{l}\text { Antibiyoterapi, ardışık } \\
\text { kompresyon-distraksiyon } \\
\text { manevraları }\end{array}$ \\
\hline 24 & Distraksiyon Osteogenezisi & 86.6 & - & \\
\hline
\end{tabular}

Adress for correspondence: İsmail Burak Atalay, Ankara Onkoloji Eğitim Ve Araştırma Hastanesi Demetevler Ankara, Türkiye

e-mail: drburakatalay@gmail.com

Available at www.actaoncologicaturcica.com

Copyright $\odot$ Ankara Onkoloji Hastanesi 
Table 4. Üst ekstremite rekonstrüksiyonu yapılan olguların fonksiyonel değerlendirilmesi

\begin{tabular}{|l|l|l|l|}
\hline OLGU NO & $\begin{array}{l}\text { ANATOMIK } \\
\text { YERLEŞIM }\end{array}$ & REKONSTRÜKSIYON & DASH SKORU \\
\hline 4 & Humerus proksimal & Vasküler segmenter fibula & 2.3 \\
\hline 5 & Humerus proksimal & $\begin{array}{l}\text { Avasküler segmenter } \\
\text { fibula }\end{array}$ & 2.0 \\
\hline 6 & Humerus proksimal & $\begin{array}{l}\text { Avasküler osteoartiküler } \\
\text { fibula }\end{array}$ & 2.50 \\
\hline 7 & Radius distal & $\begin{array}{l}\text { Avasküler osteoartiküler } \\
\text { fibula }\end{array}$ & 2.30 \\
\hline 15 & Ulna distal & $\begin{array}{l}\text { Avasküler osteoartiküler } \\
\text { fibula }\end{array}$ & 2.65 \\
\hline 16 & Klavikula & $\begin{array}{l}\text { Avasküler osteoartiküler } \\
\text { fibula }\end{array}$ & 2.0 \\
\hline ORT. & & & 2.29 \\
\hline
\end{tabular}

Tablo 5. Diz çevresi rekonstrüksiyonların fonksiyonel değerlendirilmesi

\begin{tabular}{|l|l|l|l|l|}
\hline OLGU NO & ANATOMIK YERLEŞiM & REKONSTRÜKSIYON & $\begin{array}{l}\text { KNEE SOCIETY DIZ } \\
\text { SKORU }\end{array}$ & $\begin{array}{l}\text { KNEE SOCIETY } \\
\text { FONKSIYONEL SKORU }\end{array}$ \\
\hline 1 & Tibia proksimal & Avasküler segmenter fibula & 74 & 78 \\
\hline 3 & Femur distal & Avasküler segmenter fibula & 70 & 74 \\
\hline 11 & Femur distal & $\begin{array}{l}\text { Avasküler osteoartiküler } \\
\text { fibula }\end{array}$ & 60 & 65 \\
\hline 13 & Tibia proksimal & Avasküler iliak otogreft & 70 & 74 \\
\hline 20 & Tibia proksimal & Avasküler segmenter fibula & 89 & 91 \\
\hline 23 & Tibia proksimal & Distraksiyon Osteogenezisi & 74 & 78 \\
\hline ORT. & Tibia proksimal & Distraksiyon Osteogenezisi & 70 & 74.2 \\
\hline
\end{tabular}




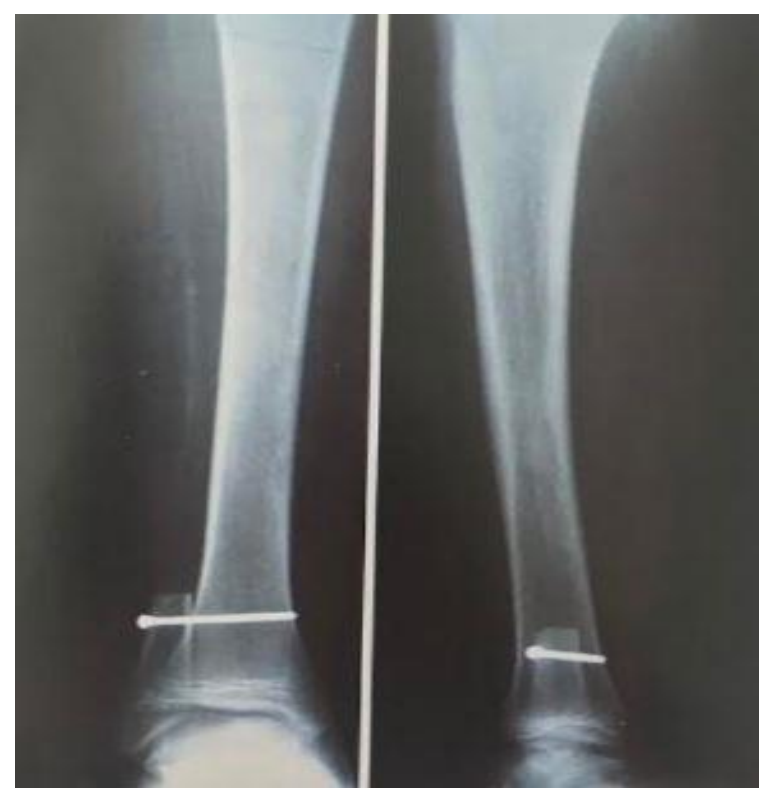

Resim 1: Valgus deformitesini ve ayak bilek lateral instabilitesini önlemek için donör sahada distal tibiofibuler eklemin sindesmoz vidası ile tespiti

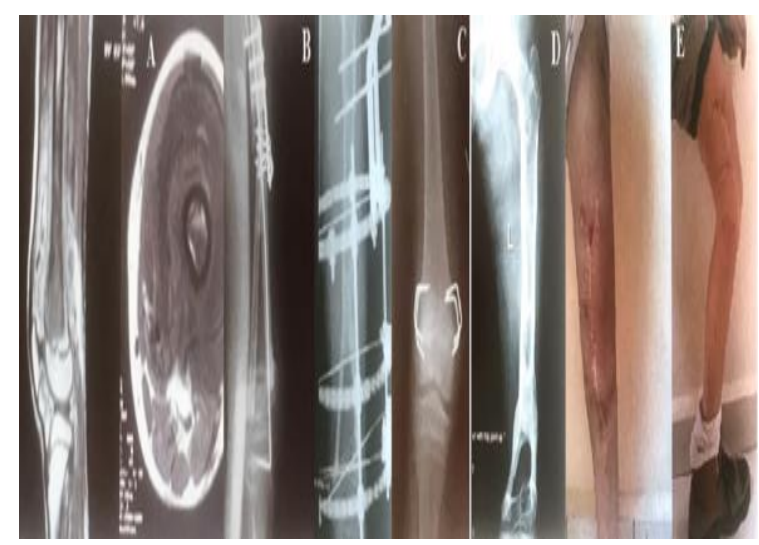

Resim 2 A: Sol femur distalde osteosarkom, B: Avasküler segmenter otogreftle plak-vida fiksasyonu nonunion, C: Sirküler eksternal fiksatör ile revizyon ve ekstremite uzunluk farkını korumak için karşı tarafa geçici epifizyodez uygulaması, D: 35.ay direk grafi E: 35 .ay knee society diz skoru 70, fonksiyonel skoru 74. (Olgu 3)

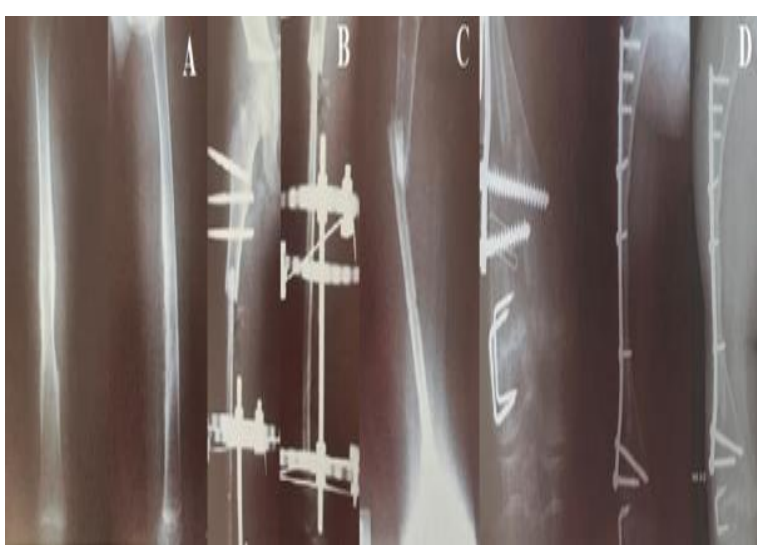

Resim 3 A: Sağ femur diafiz Ewing sarkom, B: Hibrit sirküler eksternal fiksatör yardımıyla avasküler segmenter fibuler otogreftle rekonstrüksiyon, C: İlizarov çıkarımı sonrası proksimal osteotomi hattından fraktür, D: Plak vida ile fiksasyon ve epifizyodez sonrası geç dönem (36.ay) takip grafisi (Olgu 8).

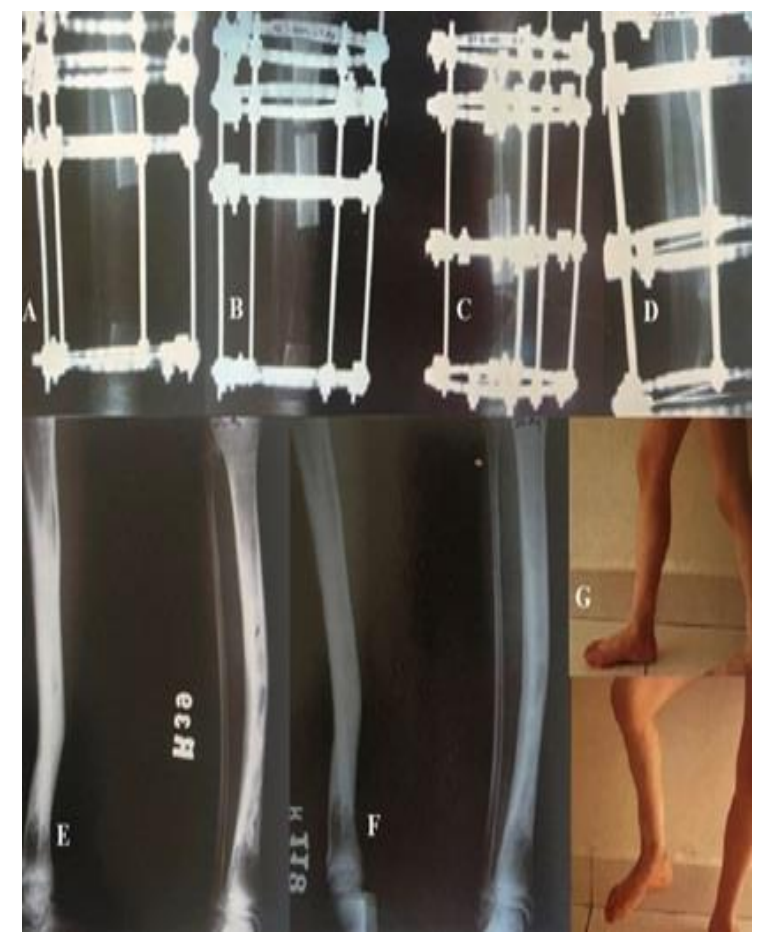

Resim 4 A: Sağ tibia distalde osteosarkom, tümör rezeksiyonu ve ilizarov sirküler eksternal fiksatör yardımıyla segment kaydırma ile biyolojik rekonstrüksiyon uygulamas1 10. Gün direk grafi B: 1.ay C: 3. Ay, D: 6.ay, E: 24.ay, F: 30.ay takip direk grafileri, G: Pin dibi enfeksiyonu ardından antibiyoterapi tedavisi sonrası klinik görünüm. MSTS skoru 73.3. (Olgu 21) 


\section{REFERENCES}

1. Erler K, Demiralp B, Ozdemir MT, Başbozkurt M. Successful results of total femoral resection and prosthetic replacement in two patients. Acta Orthop Traumatol Turc 2004; 38:79-84.

2. Damron TA. Endoprosthetic replacement following limb-sparing resection for bone sarcoma. Semin Surg Oncol 1997; 13:3-10

3. Diefenbeck M,Wagner F, Kirschner MH, Nerlich A, Muckley T, Hofmann GO. Outcome of allogenic vascularised knee transplants. Transpl Int 2007; 20:410-18

4. Krieg AH, Davidson AW, Stalley PD. Intercalary femoral reconstruction with extracorporeal irradiated autogenous bone graft in limb-salvage surgery. J Bone Joint Surg Br 2007;89:366-71

5. Futani $H$, Minamizaki $T$, Nishimoto $Y$, Abe $S$, Yabe H. Longterm follow-up after limb salvage in skeletally immature children with a primary malignant tımor of the distal end of the femur. J.Bone Joint Surg Am 2006; 88:595-603

6. Lejman T, Kowalczyk B. Biological methods in the recosntruction of massive bone defects after local resection of bone tumors in children. Orthop Traumatol Rehab 2005; 505-13

7. Stein H, Cordey J, Perren SM. Segment transport fort he biological reconstruction of bone defects. An overview. Injury 1993; 24 Suppl.2:2024

8. Mori T, Fujii M, Akisue T, Yamamoto T, Kurosaka M, Sugimura K. Three-dimensional images of contrast-enchaned MDCT for preoperative assessment of musculoskeletal masses: comparison with MRI and plain radiographs. Radiat Med 2005; 23:398-406

9. Sumikawa H, Johkoh T, Koyama M, Kozuka T, Ikemoto $\mathrm{M}$, et al. Image quality of high-resolution CT with 16-channel multidetector-row CT: comparison between helical scan and conventional step-shoot scan. Radiat Med 2005; 23:539-44

10. Skaliczki G, Antal I, Kiss J, Szalay K, Skaliczki J, Szendröi M. Functional outcome and life quality after endoprosthetic reconstruction following malignant tumours around the knee. International orthopaedics (SICOT) 2005; 29:174-78

11. Shirai T, Tsuchiya H, Yamamoto N, Sakurakichi K, Tomita K. Successful management of complications from distraction osteogenesis after osteosarcoma resection: a case report. J Orthop Sci 2004; 9:63842

12. Tsuchiya $\mathrm{H}$, tomita $\mathrm{K}$, Minematsu $\mathrm{K}$, Mori $\mathrm{Y}$, Kitano S. Limb salvage using distraction osteogenesis. A classification of the technique. British editorial Society of Bone and Joint Surgery 1997; 79B403-11

13. Lesensky J, Prince DE. Distraction osteogenesis reconstruction of large segmental bone defects

Adress for correspondence: İsmail Burak Atalay, Ankara Onkoloji Eğitim Ve Araştrrma Hastanesi Demetevler Ankara, Türkiye

e-mail: drburakatalay@gmail.com

Available at www.actaoncologicaturcica.com

Copyright $\odot$ Ankara Onkoloji Hastanesi after primary tumor resection: pitfalls and benefits. Eur J Orthop Surg Traumatol 2017; 27:715-27

14. Yang Z, Jin L, Tao H, Yang D. Reconstruction of large tibial bone defects following osteosarcoma resection using bone transport distraction: A report of two cases. Oncol Lett 2016; 12:1445-47

15. Dormans JP, Ofluoglu Ö, Erol B, Moroz L, Davidson RS. Case report: Reconstruction of an intercalary defect with bone transport after resection of Ewing's sarcoma. Clin Orthop Relat Res 2005; 434:258-64

16. Friedlander GE, Tross RB, Doganis AC, Kirkwood JM, Baron R. Effects of chemotherapeutic agents on bone: Short-term methotrexate and doxorubicin (adriamycin) treatment in a rat model. J Bone Joint Surg 1984; 66:602-7

17. Prevot J, Poncelet T, Lemelle JL, Lascombes P. Etude de l'osteogenese en distraction sur un organisme animal soumis a une chimiotherapie anti-cancereuse. Chir Ped 1988; 29: 226-30.

18. Ozaki $T$, Nakatsuka $Y$, kunisada $T$, KAwai A, Naito $\mathrm{N}$, Inoue $\mathrm{H}$. High complication rate of reconstruction using Ilizarov bone transport method in patients with bone sarcomas. Arch Orthop Trauma Surg 1998; 118:136-39.

19. Rahman MA, Bassiony A, Shalaby $H$. Reimplantation of the resected tumour-bearing segment after recycling using liquid nitrogen for osteosarcoma. Int Orthop 2009; 33:1365-370

20. Shinmura K, Murakami $H$, Demura $S$, Kato $S$, Yoshioka K, Hayashi H. Implantation of Liquid Nitrogen Frozen Tumor Tissue after Posterior Decompression and Stabilization for Metastatic Spinal Tumors. Asian Spine J 2015; 9:869-75.

21. Zaretski A, Amir A, Meller I, Leshem D, Kollender Y, Barnea Y. et al. Free fibula long bone reconstruction in orthopedic oncology: a surgical algorithm for reconstructive options. Plast. Reconstr. Surg 2004; 113:1989-2000.

22. Enneking WF, Eady JL, Burchardt H. Autogenous cortical bone grafts in the reconstruction of segmental skeletal defects. J Bone Joint Surg 1980; 62A:1039

23. Donati D, Di Liddo M, Manfrini M. Massive bone allograft reconstruction in high grade osteosarcoma. Clin Orthop 2000; 377:186-94

24. Chen MC, Disa JJ, Lee HY, Mehrara BJ. Reconstruction of extremity long bone defects after sarcoma resection with vascularized fibula flaps: A 10-Year Review. Plast Reconstr Surg 2007; 119:915-24.

25. Gonzalez-Herranz P, Del Rio A, Burgos J, LopezMondejar A, Rapariz JM. Valgus deformity after fibular resection in children. $J$ Pediatr Orthop 2003; 23:55-59. 